\title{
O REFLEXO DA ORIENTAÇÃO NA PRÁTICA DO ALEITAMENTO MATERNO
}

\author{
Mirna Albuquerque Frota ${ }^{1}$, Nicole Napoleão Soriano Aderaldo², Vanessa Gomes Silveira ${ }^{3}$, Karla Maria Carneiro Rolim4, \\ Mariana Cavalcante Martins ${ }^{5}$
}

RESUMO: Objetivamos identificar o conhecimento das mães acerca da amamentação, visando investigar sentimentos maternos a respeito dessa prática. Estudo exploratório-descritivo com abordagem qualitativa, realizado na MaternidadeEscola Assis Chateaubriand-MEAC, em Fortaleza-CE. Os sujeitos foram 10 mães assistidas por profissionais da MEAC. A coleta de dados foi de julho a agosto de 2005, com a observação participante e entrevista semi-estruturada. O conteúdo foi agrupado nas categorias: Orientações recebidas do serviço; Vantagens x desvantagens; Duração do aleitamento materno; Sentimento ao amamentar. Os dados obtidos permitiram compreender que as mulheres são conscientes dos benefícios, mas se queixam de que a amamentação é difícil, contribuindo para a introdução de alimentos complementares, podendo haver um desvio no crescimento e desenvolvimento das crianças. Concluímos que estratégias de educação em saúde são importantes, pois permitem desenvolver atividades de educar, facilitando a sensibilização das mulheres para a tomada de consciência destes valores.

PALAVRAS-CHAVES: Aleitamento Materno; Cuidado; Promoção da Saúde.

\section{GUIDANCE INFLUENCING BREASTFEEDING PRACTICE}

\begin{abstract}
We aimed to identify mothers' knowledge on breastfeeding, and to investigate maternal feelings regarding this practice. Descriptive exploratory study, with qualitative approach, carried out at the Teaching Maternity Hospital Assis Chateaubriand, in Fortaleza-Ceará State/Brazil. The subjects were 10 mothers assisted by the hospital professionals. Data collection was held from July to August/2005, with participant observation and semi-structured interview. The content was grouped in the categories: Received guidance by the service; Advantages x disadvantages; Breastfeeding duration; Breastfeeding feeling. The gathered data to apprehend that the women are aware of the benefits but complain that breastfeeding is difficult, contributing for the complementary food introduction, thus impairing child growth and development. We conclude that health education strategies are important, as they enable to develop educational activities thus facilitating women 's sensitization to the awareness of such values.
\end{abstract}

KEYWORDS: Breastfeeding; Care; Health Promotion.

\section{EL RESULTADO DE LA ORIENTACIÓN EN LA PRÁCTICA DE LA LACTANCIA MATERNA}

RESUMEN: Tuvimos como objetivo determinar qué conocimiento tienen las madres acerca de la lactancia, investigando sentimientos maternos con respecto a esa práctica. Estudio exploratório y descriptivo, con abordaje cualitativo, realizado en la Maternidade-Escola Asis Chateaubriand - MEAC, en Fortaleza, CE. Los participantes fueron 10 madres lactantes asistidas por profesionales en la MEAC. La colecta de datos se realizó entre julio y agosto/2005, mediante la observación del participante y la entrevista semi-estructurada. El contenido fue agrupado en las categorías: Orientaciones recibidas del servicio; Ventajas y Desventajas; Duración de la Lactancia Materna e Influencia del Sentimiento en la Práctica de la Lactancia Materna. Los datos obtenidos permitieron conocer que las madres lactantes están al corriente de los beneficios, no obstante se quejan de que amamantar es difícil, contribuyendo a la introducción de alimentos complementarios, lo que puede ocasionar desvío en el crecimiento y en el desarrollo de los niños. Las estrategias de educación en salud son importantes, pues permiten desarrollar actividades dirigidas a los principios de educar, facilitando la sensibilidad de las mujeres para la toma de consciencia de eses valores.

PALABRAS CLAVE: Lactancia materna; Cuidado; Promoción de la salud.

\footnotetext{
${ }^{1}$ Doutora em Enfermagem. Docente da Graduação em Enfermagem e Mestrado em Saúde Coletiva. Universidade de Fortaleza-UNIFOR. Orientadora.

${ }^{2}$ Enfermeira. Universidade de Fortaleza-UNIFOR.

${ }^{3}$ Acadêmica do $7^{\circ}$ Semestre Curso de Nutrição. Universidade de Fortaleza-UNIFOR.

${ }^{4}$ Doutora em Enfermagem. Docente da Graduação em Enfermagem da Universidade de Fortaleza-UNIFOR.

${ }^{5}$ Doutoranda em Enfermagem. Universidade Federal do Ceará-UFC.
}

Autor correspondente:

Mirna Albuquerque Frota

Rua Manoel Jacaré, 150 - 60175-110 - Fortaleza-CE

E-mail:mirnafrota@unifor.br

Recebido: 30/04/08

Aprovado: 05/06/08 


\section{INTRODUÇÃO}

A amamentação colabora para o crescimento e desenvolvimento infantil devido aos benefícios de ordem nutricional, imunológica, econômica, psicológica e ecológica. Essa prática é a principal escolha para a criança, já que agrega noções fundamentais de nutrição adequada como o alimento, a saúde e os cuidados ${ }^{(1)}$.

Existem evidências de que infantes amamentados ao seio apresentam melhores resultados em testes de inteligência, desenvolvimento cognitivo, o que revela inúmeras vantagens para esta atividade, facilitando a maturação gastrintestinal, o vínculo mãefilho, o desempenho neurocomportamental, a menor incidência de infecção e a re-hospitalização. Assim, o exercício do contato precoce entre o binômio mãefilho é recomendável para promoção do aleitamento materno, alicerçando-se no conhecimento de que os laços afetivos são mais fortes nas primeiras duas horas de vida, e que este vínculo é primordial para o início e a manutenção do aleitamento materno exclusivo ${ }^{(2-3)}$.

O leite materno e suas vantagens são reconhecidos, mas o emprego da amamentação não ocorre de forma adequada. O desmame precoce, principalmente em populações de baixa condição sócioeconômica, aumenta a morbimortalidade das crianças e compromete o crescimento e desenvolvimento destas. Esta dificuldade se revela um problema de saúde pública, pois é crescente o número de mães que optam por outros tipos de alimentos em detrimento do leite materno, por razões muitas vezes enraizadas nos aspectos culturais da população, que acredita que os alimentos lácteos não-maternos podem trazer tantos ou maiores benefícios para o filho.

A introdução de outro tipo de alimento pode interferir na absorção de nutrientes, levando a carências nutricionais, pois são utilizados alimentos inadequados para o lactente, o que pode acarretar alergia alimentar e, a longo prazo, doenças como hipertensão, arteriosclerose, obesidade e diabetes mellitus. Além das condições culturais, os fatores sociais, psíquicos e biológicos resultam em um processo acumulativo de informações e conhecimentos transmitidos de geração em geração, que influenciam diretamente no processo da amamentação ${ }^{(4)}$.

Muitas vezes, mães não concretizam a amamentação, relatando que a causa do desmame é devido ao seu leite ser fraco e não sustentar, além de associarem essa situação a um freqüente e intenso choro do bebê. A percepção da mãe, ao considerar que seu leite é impróprio para suprir as necessidades nutricionais da criança é uma razão para a interrupção prematura da amamentação ao seio, podendo ser conseqüência de uma má orientação dos serviços de saúde. Estes não informam que as causas do choro após a amamentação podem estar relacionadas a problemas orgânicos, fisiológicos (cólicas), sucção inadequada das mamas, sucção com aréola distendida, dentre outros ${ }^{(5-6)}$.

Assim, o profissional tem papel fundamental nas orientações de promoção da saúde por meio da educação com o desenvolvimento da consciência crítica, viabilizando pontos positivos como também negativos e dificuldades dentro de um contexto social para realização de determinada prática.

A capacidade de produção do leite materno é maior do que o apetite da criança, ressaltando-se que aquele alimento fornece água, sais minerais, vitaminas, carboidratos, proteínas e gorduras indispensáveis ao recém-nascido. Esta é uma razão relevante para que as políticas de saúde estimulem programas de intervenção e programas educacionais que orientem as mães para os benefícios e o manejo da amamentação ${ }^{(6-7)}$.

O aleitamento materno ocupa lugar de destaque entre as ações básicas de saúde recomendadas pela Organização Mundial de Saúde (OMS), a fim de diminuir a morbidade e a mortalidade e melhorar a qualidade de vida das crianças, sendo preconizado exclusivo até os seis meses de vida. Nestes, até então, não é necessário água, chás ou vitaminas. Depois, introduzir alimentação complementar é recomendado para suprir suas demandas nutricionais, devendo dar continuidade à amamentação por até dois anos de idade. Esta duração do aleitamento materno está relacionada com fatores clínicos, socioeconômicos, características da mãe da criança, bem como orientações e atitudes sobre o planejamento familiar ${ }^{(8)}$.

O leite materno ainda prepara a criança para a introdução gradativa da alimentação complementar. Há, no primeiro ano, mudanças no desenvolvimento do sistema nervoso central, que fornece maturidade para o infante suportar ou até mesmo aceitar a dieta da família, a qual contém diversificadas texturas. A introdução de alimentos sólidos deve ocorrer paralelamente a essas mudanças. A alimentação, no decorrer desse primeiro ano de vida, altera-se à medida que o sistema gastrintestinal desenvolve-se e se torna capaz de metabolizar seus componentes ${ }^{(9)}$.

Embora as vantagens do leite materno estejam 
amplamente comprovadas, há necessidade de enfocar sobretudo as desvantagens da não prática para o binômio mãe-filho, como: predisposição a desnutrição infantil, ocorrência de doenças parasitárias, comprometimento no crescimento e desenvolvimento, diminuição do vínculo mãe e filho, dentre outros. Para tanto é necessário maior sensibilização dos profissionais de saúde e da sociedade, para que seja desenvolvido um trabalho de impacto sobre a cobertura de aleitamento na busca da redução da morbimortalidade infantil e o compromisso com a humanização do atendimento à puérpera.

Os índices de aleitamento materno têm se mostrado abaixo das expectativas e esse impacto na sua duração é acarretado pela falta de informação das mães e da sociedade. Assim, objetivamos no presente artigo identificar o conhecimento das mães acerca da amamentação, com enfoque nas orientações recebidas nas unidades de saúde.

\section{MATERIAIS E MÉTODOS}

Estudo do tipo exploratório-descritivo, com abordagem qualitativa, caracterizado por ser complexo, requerer reflexões mais profundas das ações e relações humanas, incluindo valores, crenças que não podem ser operacionalizados em variáveis, ou seja, baseia-se em palavras, histórias, preocupando-se com o microssocial, ao aplicar métodos indutivos como estratégias para obter a informação do participante. Assim, dentre as formas de coletas dos dados da pesquisa qualitativa, utilizamos a entrevista semiestruturada, a qual nos permite enumerar as questões que o pesquisador quer abordar no campo, a partir de suas hipóteses ou pressupostos, proporcionando ao informante liberdade de expressão(10).

As informantes da pesquisa foram 10 mães assistidas no Setor de Alojamento Conjunto da Maternidade-Escola Assis Chateaubriand - MEAC, na cidade de Fortaleza-CE, sendo convidadas a participarem da pesquisa após aprovação do presente estudo pela Comissão de Ética Médica da MEAC Universidade Federal do Ceará/UFC, ofício de n. 109/ 05 e protocolo de n. 42/05.

A coleta de dados foi realizada de julho a agosto de 2005. Durante o primeiro contato com as participantes evidenciamos os objetivos e finalidades do estudo como também os princípios da bioética baseados na Resolução de nº 196/96 que regulamenta pesquisas que envolvem seres humanos, ressaltando que o entrevistado tem direito de recusar-se a participar da pesquisa em qualquer momento. Foi assinado o Termo de Consentimento Livre e Esclarecido após aceitarem participar da pesquisa, com ênfase que seria mantido sigilo sob os dados pessoais, como nome do cliente entrevistado sendo utilizado cognomes (Mãe1, Mãe2 - Mãe 10).

Em continuidade, foi aprazada a data, horário e local - MEAC, para a realização das entrevistas semiestruturada que foram norteadas pelas seguintes questões: Durante as consultas de enfermagem você é orientada sobre as vantagens do aleitamento materno exclusivo? Quais? Exemplifique algumas vantagens e/ou dificuldades da amamentação; Por quanto tempo deve-se amamentar? Como você se sente ao amamentar? Estas foram gravadas e transcritas para posterior análise. Em complementação as entrevistas utilizamos a observação participante.O registro no diário de campo possibilitou uma descrição detalhada do contexto de cada mãe.

As informações das entrevistas e o diário de campo foram analisados baseado nos princípios de Minayo $^{(11)}$, que prossegue com a classificação dos dados, a fim de identificar idéias centrais, elaborando categorias para análise final, nas quais foram confrontados com textos que abordam a temática estudada, revelando, nas informações coletadas, a especificidade de concepção.

\section{RESULTADOS E DISCUSSÃO}

Partindo da análise dos discursos das mães e mediante saturação das respostas, emergiram as categorias: Orientações recebidas do serviço; Vantagens x desvantagens; Duração do aleitamento materno; Sentimento ao amamentar.

\section{Orientações recebidas do serviço}

Nesta categoria constatamos que as gestantes são orientadas durante o Pré-Natal, mas demonstram deficiência quanto à importância do aleitamento materno. É preciso salientar que orientações não devem ser repassadas, mas orientadas de forma contextualizada e dentro das particularidades de cada mãe.

Após o nascimento do filho, as mães, na maioria das vezes, percebem-se inseguras e involuntariamente comprometem um momento que poderia ser favorável como o ato de amamentar. Portanto, a amamentação é realizada de forma incorreta e a introdução da 
alimentação complementar ocorre precocemente.

Sim. Ela dizia para não deixar de amamentar o filho porque é muito bom, se ele não conseguir pegar o peito, esvazie e dê a ele. Falava cada coisa e eu ainda nem pensava em ter ainda, toda consulta falava sobre o peito. Ah! meu Deus do céu! Dava quatro meses de gestação e ela falando sobre isso. Eu dizia: Minha filha, eu não quero saber disso agora. Só no final que interessou (Mãe.1)

Falavam que prevenia as doenças, não ficava com diarréia, essas coisas assim (Mãe.2).

Em contrapartida existiu uma mãe que evidenciou:

\section{Não. Não sou orientada (Mãe.3).}

É útil destacar que as mães, principalmente as primíparas, precisam de ajuda para iniciar, com sucesso, a amamentação e que estas podem estar mais flexíveis a receber orientações no pré-natal, no final da gestação. Ainda, que existem dificuldades na implantação de estratégias para incentivar este exercício, porém os resultados são satisfatórios, verificando um aumento nos índices de aleitamento exclusivo e uma humanização no atendimento materno-infantil.

Os profissionais valorizam a relação com as mães, estimulando o resgate desta prática. As orientações para educação em saúde devem começar a partir da realidade de cada uma das mães, determinando prioridades, e tendo em vista suas necessidades e recursos ${ }^{(12)}$. Entretanto, conhecendo as vantagens do leite materno para o bebê, alguns profissionais, ansiosos em promover o aleitamento materno, podem repassar uma idéia de cobrança a mãe, respaldando seu discurso nas comprovações científicas que realçam o valor do leite humano.

\section{Vantagens $x$ Desvantagens}

Estudo $^{(13)}$ mostra que crianças amamentadas exclusivamente nos seis primeiros meses de vida apresentaram ganho ponderal correspondente aos padrões de normalidade. Estas conseguem dobrar o peso de nascimento antes do quarto mês de vida, chegando aos seis meses eutróficas.

O crescimento estatural também é referido e se apresenta adequado, quando comparado às referências.
Assim, comprova-se que o leite materno é ideal para um crescimento e desenvolvimento saudável, sem a necessidade de complementar a alimentação ${ }^{(13)}$.

Mesmo que a mãe saiba que o leite materno é rico e adequado para o recém-nascido e dispensa a necessidade de outro alimento até os seis meses de idade, entretanto, essa vantagem entra em confronto com as desvantagens/dificuldades evidenciadas, como a dor no ato da amamentação.

Sim. Quando amamento dói muito. As vezes fica ferido porque quando o neném suga aperta bastante e é desconfortável (Mãe.5).

Diante do relato, pode-se evidenciar que a mãe julga ser desvantagem amamentar diante de uma dificuldade enfrentada. Assim, o profissional de enfermagem deve ajuda-la no momento de desespero e desistência da prática da amamentação, sendo esta atitude importante para a sua continuidade. O profissional não deve desprezar tal relato, mas conciliar vantagens diante das dificuldades.

Sabe-se que a amamentação é uma prática difícil de ser alcançada na sua integralidade, já que as mães criticam o desconforto, a dor e a estafa física e mental. Nessa categoria, foi possível perceber que as mães possuem uma informação pouco sólida sobre o assunto, têm ciência de que a amamentação é significante, mas não evidenciam ser imprescindível.

A gente volta em forma mais rápido, já me informaram sobre isso. Eu, pelo menos, me sinto muito bem amamentando (Mãe.4).

As desigualdades sociais, culturais e financeiras interferem, e as comunidades carentes são mais prejudicadas. Deste modo, se faz relevante estimular programas de intervenção e programas educacionais que norteiem as mães para as vantagens e o manejo da amamentação.

O leite materno atua como agente imunizador, acalenta a criança no aspecto psicológico, tem vantagem técnica por ser operacionalmente mais simples, é de baixo custo, protege a mulher contra câncer mamário e ovariano, auxilia na involução uterina, retarda a volta da fertilidade, e otimiza o papel de mãe. Além disso, há eficácia dos fatores de proteção, destacando até mesmo sua ação em patologias que têm exigido atenção no atual cenário da saúde pública, como cólera e dengue, cujos agentes 
causais são combatidos com eficiência por constituintes específicos do leite humano ${ }^{(14)}$.

É. Porque ele contém todas as vitaminas que no aleitamento materno tem. $O$ intestino dele não pode aceitar qualquer coisa e o leite materno foi feito para ele (Mãe.2).

O colostro que tem todas as vitaminas que o recém nascido precisa (Mãe.3).

Ganha peso mais rápido, ajuda quando está nascendo os dentes (Mãe.4).

Face ao exposto, a falta de informação é sem dúvida um fator prejudicial intercalado com os saberes populares e culturais, pois se as mães conhecessem a função do aleitamento materno, não abdicariam dessa atividade, mesmo com as dificuldades enfrentadas no contexto sócio-econômico. No entanto, deve-se privilegiar ações que contemplem a introjeção de novos valores culturais em favor da amamentação, valores esses que considerem-na como um ato que precisa ser aprendido pela mulher e protegido pela sociedade ${ }^{(15)}$.

\section{Duração do aleitamento materno}

Esta foi uma categoria que emergiu e chamou atenção, pois diante dos depoimentos as mães relataram a prática do aleitamento materno com duração de seis meses, não mais que isso. Esse conceito é diferente do preconizado pelo Ministério da Saúde, o qual recomenda até seis meses e oferecer a mama de forma exclusiva, devendo ser complementada até os dois anos.

No mínimo seis meses. Mas agora agente já está sabendo que é enquanto a criança quiser mamar. E a gente puder (Mãe.5).

É para dar mama no máximo seis meses (Mãe.6).

Dou seis meses e depois mingau (Mãe.7).

A Organização Mundial da Saúde ${ }^{(16)}$ sugere que, mesmo que surjam argumentos contrários à recomendação quanto à duração do aleitamento materno, continua prevalecendo a recomendação de que as crianças sejam amamentadas preferencialmente por dois anos ou mais, pois o leite materno pode ser importante fonte de nutrientes após o primeiro ano e continuando como fonte de gordura, vitamina A, cálcio e riboflavina no segundo ano de vida.

É importante salientar, que as mães nutrizes não amamentam seus filhos em período maior, refletindo suas dificuldades socioeconômicas relacionando com o retorno a jornada de trabalho de forma precoce, para auxiliar nas despesas domésticas tendo em vista, na maioria das vezes, a sustentabilidade de outros filhos.

Foi possível inferir, com a observação durante a realização das entrevistas no Alojamento Conjunto, que a desinformação sobre a duração do aleitamento materno, assim como o desconforto e técnica incorreta, são resultados de um acompanhamento fragmentado na atenção básica.

Todavia, o enfermeiro deve despertar para a importância de educação em saúde durante o PréNatal de forma eficaz e continuada, expandindo até os seis primeiros meses da criança. A finalidade é desenvolver uma consciência crítica nas gestantes, e obter o empoderamento em relação ao Aleitamento Materno Exclusivo, até os seis meses e sua continuidade até os dois anos, não esquecendo o âmbito cultural e sócio-econômico em que a família está inserida.

Os índices inferiores com relação à prática do aleitamento materno exclusivo reforçam a necessidade de continuar estimulando a amamentação nos primeiros meses de vida, já que esta agrega uma maior segurança, além de ser econômica e emocionalmente satisfatória para a alimentação dos bebês, sobretudo nos países em desenvolvimento ${ }^{(17)}$. Desse modo, os benefícios da amamentação são evidentes. Entretanto, o reconhecimento dessa realidade tem levado à busca das causas e da freqüente interrupção do aleitamento exclusivo.

O desmame precoce em países em desenvolvimento ocorre com freqüência, o que pode vir a contribuir para a incidência da desnutrição. De modo geral, a desnutrição corresponde a uma patogenia de carência da ingestão calórico-protéica, sendo um estado crônico, no qual o organismo apresenta uma desaceleração, podendo ter interrupção da evolução normal, com prejuízos bioquímicos e funcionais, ocasionando agravos irreparáveis em suas vidas ${ }^{(18)}$.

\section{Sentimento ao amamentar}

Com relação ao significado dado pelas mães, o ato de amamentar ainda apresenta obstáculos, existindo incertezas na realização dessa prática, 
gerando sentimentos de culpa, muitas vezes ligadas ao fato de ser mãe e concomitantemente possuir várias responsabilidades inerentes ao lar.

Partimos da definição do dicionário Aurélio ${ }^{(19)}$, de que sentimentos, são informações que seres biológicos são capazes de sentir nas situações que vivenciam. Portanto, é mediante a vivência em amamentar que sentimentos emergem. A prática de amamentar estabelece o primeiro vínculo com a criança e passam, os dois, a vivenciar esse contato, que servirá de base para o desenvolvimento emocional do bebê, sobretudo no início da vida.

Me sinto bem. Fico satisfeita, porque sei que vai ser uma coisa boa prá ele. Prá mim também que vai fazer meu peso voltar ao normal (Mãe.2).

É bom demais. Agora, a gente fica cansada. Mas é menos trabalho, só em não se levantar prá fazer mamadeira. Aqui está tudo feitinho (Mãe.3).

Ah! Muito bom. Estou muito realizada, muito feliz (Mãe.4).

As mães mencionaram sentimentos de satisfação e felicidade ao perceber as vantagens que o aleitamento pode proporcionar ao binômio mãe-filho. Por outro lado, elas verbalizaram que o ato de amamentar ocasiona cansaço, demandando maior dedicação. É nessa perspectiva que essas dúvidas devem ser esclarecidas e apoiadas por um profissional, em especial, o enfermeiro.

O elo estabelecido entre mãe e filho é importante para o relacionamento posterior, assim como a relação durante a amamentação, que surge espontaneamente, começando pela compatibilidade física até formar um vínculo. A interação durante o aleitamento materno interfere na qualidade dessa prática, proporcionando oportunidade de contato físico e visual e a vivência da cooperação entre a mãe e o bebê. $\mathrm{O}$ binômio tem a necessidade um do outro, física e emocionalmente, portanto, a criança precisa da amamentação, além do contato com a progenitora. Isto dito, deve o profissional adotar condutas de forma a apoiar e fortalecer esse ato, sendo necessário assistir o individuo, a família e a comunidade $^{(20)}$.

Contudo, não se pode incutir o sentimento de culpa nas progenitoras que não querem ou não podem amamentar, ao contrário, se deve fornecer, nestes casos, informações e conhecimentos adequados à prática de uma alimentação complementar, além de exaltar as vantagens da amamentação não só para os bebês, mas para o binômio mãe-filho, na tentativa de despertar o interesse e o prazer durante a lactação.

\section{CONSIDERAÇÕES FINAIS}

O aleitamento materno tem importância no desenvolvimento e crescimento da criança, para tanto, cabe aos profissionais da saúde a responsabilidade para sensibilizar as gestantes das vantagens desta prática, visto que é oportunizado um maior contato com as mulheres no período de pré-natal. As mulheres oferecem este vínculo de confiança e credibilidade aos profissionais, seja pela conjuntura atual ou pela disponibilidade que este fornece no ato de comunicar. Portanto, a preparação no ciclo gravídico-puerperal é realizada a fim de que ocorra uma amamentação livre de queixas e desenvolva a tomada de consciência dos benefícios trazidos pelo ato de amamentar.

Nas Unidades Básicas de Saúde, os profissionais encontram-se numa posição ideal para promover uma mudança por meio de um papel preventivo, contribuindo. Na educação e promoção do ato de amamentar, para uma prática simples e instintiva que pode auxiliar muitas crianças. O encorajamento da amamentação é necessário para que mães e familiares participem deste processo de saúde. Embora o valor do leite materno para a saúde da criança, bem como seu benefício econômico para o país sejam inquestionáveis, o emprego da amamentação não ocorre de forma adequada, contribuindo, assim, para sua precoce interrupção, podendo expor a criança aos riscos de desnutrição e infecção, comprometendo sua saúde, principalmente em populações de baixa condição sócio-econômica.

Diante dessas considerações, os profissionais devem buscar um aprofundamento sobre as dificuldades do aleitamento materno, para que possam proporcionar às nulíparas alternativas importantes e indispensáveis para evitar o desmame. Há uma preocupação quanto à introdução de uma alimentação complementar precoce, pois, apesar do conhecimento, as mães queixam-se da sua dificuldade, contribuindo para a introdução antecipada de alimentos antes de seis meses, podendo induzir a um possível desvio no padrão de crescimento e desenvolvimentos destes infantes. Considerando, ainda, que outras doenças poderão vir a surgir, haja vista o comprometimento do sistema imunológico da criança.

Por conseguinte, a informação continuada com 
as mulheres é benéfica para a prática da amamentação. Para isto, seria necessário criar grupos, proporcionando troca de conhecimentos entre as mães, visto que vivenciam situações e experiências diferentes, permitindo uma participação e, logo, uma aprendizagem significativa. Poderão, ainda, ser promovidas palestras educativas, com temas de interesse, respeitando as dúvidas que emergem no momento da gestação. A assistência deverá ser abordada não somente no ciclo gestacional, mas no decorrer do ciclo puerperal e de lactação, vislumbrando a continuidade do processo ao longo do desenvolvimento do lactente.

A educação em saúde pode ser um instrumento valioso, visto que permite desenvolver atividades direcionadas aos princípios de educar, facilitando, com isso, a sensibilização das mães para a tomada de consciência destes valores. Portanto, a possibilidade de mudança correlaciona-se à credibilidade dos profissionais de saúde e à sua disponibilidade como agentes de transformação social.

\section{REFERÊNCIAS}

1. Vasconcelos MGL, Lira PIC, Lima MC. Duração e fatores associados ao aleitamento materno em crianças menores de 24 meses de idade no estado de Pernambuco. Rev. Bras Saúde Mater Infant. 2006; 6(1):99-105.

2. Reis AMC, Nascimento AL, Mazzi C, Carmona MVG, Lindholm RR. Prevalência da desnutrição e do aleitamento materno exclusivo. Estudo de alguns fatores. Nursing. 2004;69(7):130-8.

3. Serra SOA, Scochi CGS. Dificuldades maternas no processo de aleitamento materno de prematuros em uma UTI neonatal. Rev Latino-Am Enferm. 2002;12(4):597-605.

4. Rezende MA, Sigaud CHS, Veríssimo MR, Chiesa AM, Bertolozzi MR. O processo de comunicação na promoção do aleitamento materno. Rev Latino-Am Enferm. 2002;2:234-8.

5. Spyrides MHC, Struchiner CJ, Barbosa MTS, Kac G. Efeito das práticas alimentares sobre o crescimento infantil. Rev Bras Saude Mater Infant. 2005; 5(2):145-53.

6. Sonego J, Van Der Sand ICP, Almeida AM, Gomes FA. Experiência do desmame entre mulheres de uma mesma família. Rev Esc Enferm USP. 2004; 389(1):341-9.

7. Sousa JM, Sousa FGM. Aleitamento materno e o discurso da temática em revistas populares. Rev Paul Enferm. 2005; 24(3):4-11.
8. Tabai KC, Carvalho JF, Salay E. Aleitamento materno e a prática de desmame em duas comunidades rurais de Piracicaba-SP. Rev Nutr. 1998; 11( 2):173-83.

9. Almeida JAP. Amamentação: um híbrido naturezacultura. Rio de Janeiro: Fiocruz; 2002.

10. Minayo MCS. Pesquisa social: teoria, método e criatividade. Petrópolis: Vozes; 2001.

11. Minayo MCS. O desafio do conhecimento: pesquisa qualitativa em saúde. 9a ed. São Paulo: Hucitec Abrasco; 2006.

12. Frota MA, Sousa RMV, Sousa Filho OA, Barroso MGT. Diagnóstico das necessidades humanas básicas no contexto sócio-familiar de crianças desnutridas. Cogitare Enferm. 2007; 12(2):198-203.

13. Marques RFSV, Lopez FA, Braga JAP. O crescimento de crianças alimentadas com leite materno exclusivo nos primeiros 6 meses de vida. J Ped. 2004; 80(2): 99-105.

14. Ichisato SMT, Shimo AKK. Revisitando o desmame precoce através de recortes da história. Rev Latino-Am Enferm. 2002; 10(4):578-85.

15. Ramos CV, Almeida JAG. Alegações maternas para o desmame: estudo qualitativo. J Ped. 2003;79(5):385-90.

16. OMS. Organização Mundial de Saúde. Evidências científicas dos dez passos para o sucesso do aleitamento materno. Brasília: OPAS; 2001.

17. Mascarenhas MLW, Albernaz EP, Silva MB, Silveira RB. Prevalência de aleitamento materno exclusivo nos 3 primeiros meses de vida e seus determinantes no sul do Brasil. J Ped. 2006; 82(4):289-94.

18. Reis AMC, Nascimento AL, Carmona MVG, Lindhoim RR. Prevalência da desnutrição e do aleitamento materno exclusivo - estudo de alguns fatores. Nursing. 2004; 69(7):17-21.

19. Ferreira ABH. Novo Dicionário da Língua Portuguesa. 2ed. Rio de Janeiro: Editora Nova Fronteira; 1986

20. Machado TCM, Ueji JY. Cuidando de uma família de acordo com o modelo calgary em uma unidade básica de saúde da cidade de Marília - SP. REME- Rev Min Enferm. 2006; 10(1):69-74. 